\title{
Influence of the Size and Distribution of Load on the Damping Coefficient of Shock Absorbers in Passenger Vehicles
}

\author{
Jarosław Gonera' \\ 1 Department of Vehicle and Machinery Construction and Operation, Faculty of Technical Sciences, University \\ of Warmia and Mazury in Olsztyn, ul. Oczapowskiego 11/d8, 10-719 Olsztyn, Poland \\ e-mail: jaroslaw.gonera@uwm.edu.pl
}

\begin{abstract}
This paper analyses the changes in the values of the damping coefficient of shock absorbers, depending on the size and distribution of loads in passenger vehicles. The tests were conducted in two stages. During the first stage, the influence of the size of a load in vehicles, and changes in the tyre pressure values on the damping coefficient of shock absorbers was defined. During the second stage, the influence of the changes of the damping coefficient of shock absorbers was researched, depending on the size and distribution of load in passenger vehicles with various suspension systems of front and rear axles, different kerb weights, lengths and wheel bases. Eight variants of load distribution in vehicles were tested. The evaluation of the damping coefficient of shock absorbers was conducted with the EUSAMA method. This paper identified the sizes and distribution of loads in the vehicles of varied structural parameters and tyre pressures on the damping coefficient values of shock absorbers. The test results indicate that when using a vehicle under varied load conditions, there are changes in the damping coefficient of shock absorbers. This may translate directly into the traction characteristics and stability of a vehicle while travelling, and this, in turn, is connected with the vehicle safety. This paper shows the considerable influence of the tyre pressure on the EUSAMA coefficient. The changes in the vehicle loads also influenced the values of the damping coefficient of shock absorbers. The changes in the damping coefficient of shock absorbers were also influenced by the size and distribution of loads in vehicles.
\end{abstract}

Keywords: Passenger vehicles; EUSAMA coefficient; tyre pressure; mass distribution; load distribution; shock absorber.

\section{INTRODUCTION}

While travelling, a vehicle is a complex vibrating system with a large number of discretion degrees, excited by (among others) the irregularities of the road surface, operation of the engine and the drive system. The majority of the vibrations are dampened by the suspension system, but part of them reaches the body of a vehicle $[1,2$, $10,18]$. A vital role in decreasing the level of vibrations is played by shock absorbers. If excessively large vibrations are transferred to the passenger space, they may cause discomfort and may be harmful to the health of drivers and passengers $[12,14]$. For many years, there have been attempts to provide for the best isolation of drivers and passengers from road conditions, by developing high damping coefficient shock absorbers [3, $11,14]$. In addition, through the construction and characteristics of shock absorbers and springs in suspensions, the goal is to decrease the frequency and amplitude of vibrations $[4,7,11]$. Aside from comfort, the suspension system is also crucial for ensuring the safety of travellers [9]. There have been studies $[16,17]$ that considered the question of safety during the vehicle travel depending on the load of a vehicle. Fast damping of vibrations by the suspension system positively influences the stability during travel. It may be achieved only when shock absorbers feature a high damping coefficient [4]. Shock absorbers influence the vehicle travel not only when road irregularities 
are covered or in curves, but also when accelerating and, especially, when braking [6]. At that time, there is a change in the distribution of mass over the individual axles of the vehicle and the distribution of mass is connected with the damping coefficient of shock absorbers. Owing to the above-mentioned reasons, when the vehicle is used, constant changes in the damping coefficient values may occur.

A decrease in the load value influencing the vehicle body and improvement in the vehicle steering properties stems from the structure of the suspension system and the steering system. In [15] it was noted that the driveability and stability of a vehicle may change depending on the stiffness and resilience of the suspension system. On the other hand, the parameters of the suspension system while travelling are influenced by ambient temperature, type of tyres, tyre pressure and vehicle load conditions. Thus, the initial parameters of the shock absorbers operation do not guarantee proper driveability of a vehicle when used under varied load conditions and varied environmental conditions [5, 15]. Keeping all components in the right technical condition may provide the user with improved safety [8]. One of the parameters that are decisive for the level of safety of vehicles is the proper technical condition of shock absorbers [13].

This paper identified the sizes and distribution of loads in the vehicles of varied structural parameters and tyre pressures on the damping coefficient values of shock absorbers.

\section{RESEARCH METHODOLOGY}

The tests were carried out in two stages. The first stage was used to evaluate the influence of the size and distribution of load, as well as tyre pressure on the change of the damping coefficient of shock absorbers in passenger vehicles (Table 1). These were vehicles constructed on the same floorpan, equipped with identical engines, gearboxes and featuring the $4 \times 4$ drive systems. The vehicles were an SUV and a D-segment vehicle, according to the European classification, with a station-wagon-type body. The vehicles were produced in 2012, and their mileage at the time of the tests was approximately $120,000 \mathrm{~km}$.

In the second stage, the vehicles with varied front and rear axle suspension systems were tested (Table 2). They were equipped with the multi-suspension arm systems for the front and rear axles,

Table 1. Characteristics of the vehicles tested in the first stage

\begin{tabular}{|c|c|c|c|c|c|c|c|}
\hline Model & $\begin{array}{c}\text { Type of front axle } \\
\text { suspension }\end{array}$ & $\begin{array}{c}\text { Type of rear axle } \\
\text { suspension }\end{array}$ & $\begin{array}{c}\text { Kerb } \\
\text { weight [kg] }\end{array}$ & $\begin{array}{c}\text { Vehicle } \\
\text { segment }\end{array}$ & $\begin{array}{c}\text { Body } \\
\text { type }\end{array}$ & $\begin{array}{c}\text { Length } \\
{[\mathrm{mm}]}\end{array}$ & $\begin{array}{c}\text { Wheel base } \\
{[\mathrm{mm}]}\end{array}$ \\
\hline K01 & $\begin{array}{c}\text { independent }- \text { multi- } \\
\text { suspension arm }\end{array}$ & $\begin{array}{c}\text { independent }- \text { multi- } \\
\text { suspension arm }\end{array}$ & 2,085 & SUV & SUV & 4,630 & 2,810 \\
\hline K02 & $\begin{array}{c}\text { independent - multi- } \\
\text { suspension arm }\end{array}$ & $\begin{array}{c}\text { independent - multi- } \\
\text { suspension arm }\end{array}$ & 1,770 & D & wagon & 4,703 & 2,810 \\
\hline
\end{tabular}

Table 2. Characteristics of the vehicles tested in the second stage

\begin{tabular}{|c|c|c|c|c|c|c|c|}
\hline Model & $\begin{array}{l}\text { Type of front axle } \\
\text { suspension }\end{array}$ & $\begin{array}{l}\text { Type of rear axle } \\
\text { suspension }\end{array}$ & $\begin{array}{c}\text { Kerb } \\
\text { weight } \\
{[\mathrm{kg}]}\end{array}$ & $\begin{array}{l}\text { Mileage }[\mathrm{km}] / \\
\text { Production Year }\end{array}$ & Body type & $\begin{array}{l}\text { Length } \\
{[\mathrm{mm}]}\end{array}$ & $\begin{array}{c}\text { Wheel } \\
\text { base } \\
{[\mathrm{mm}]}\end{array}$ \\
\hline P01 & $\begin{array}{l}\text { independent - multi- } \\
\text { suspension arm }\end{array}$ & $\begin{array}{l}\text { independent - multi- } \\
\text { suspension arm }\end{array}$ & 1,675 & $\begin{array}{c}150,000 / \\
2004\end{array}$ & wagon & 4,841 & 2,888 \\
\hline P02 & $\begin{array}{l}\text { independent - multi- } \\
\text { suspension arm }\end{array}$ & $\begin{array}{l}\text { independent - multi- } \\
\text { suspension arm }\end{array}$ & 1,655 & $\begin{array}{c}180,000 / \\
2003\end{array}$ & wagon & 4,806 & 2,830 \\
\hline $\mathrm{R} 03$ & $\begin{array}{l}\text { independent - multi- } \\
\text { suspension arm }\end{array}$ & $\begin{array}{l}\text { semi-independent - } \\
\text { with twist beam }\end{array}$ & 1,525 & $\begin{array}{c}180,000 / \\
2002\end{array}$ & wagon & 4,796 & 2,760 \\
\hline $\mathrm{R} 04$ & $\begin{array}{l}\text { independent - multi- } \\
\text { suspension arm }\end{array}$ & $\begin{array}{l}\text { semi-independent - } \\
\text { with twist beam }\end{array}$ & 1,560 & $\begin{array}{c}160,000 / \\
2003\end{array}$ & wagon & 4,682 & 2,705 \\
\hline T05 & $\begin{array}{l}\text { independent - } \\
\text { MacPherson strut }\end{array}$ & $\begin{array}{l}\text { independent - multi- } \\
\text { suspension arm }\end{array}$ & 1,370 & $\begin{array}{c}170,000 / \\
2008\end{array}$ & hatchback & 4,150 & 2,570 \\
\hline T06 & $\begin{array}{c}\text { independent - } \\
\text { MacPherson strut }\end{array}$ & $\begin{array}{l}\text { independent - multi- } \\
\text { suspension arm }\end{array}$ & 1,300 & $\begin{array}{c}165,000 / \\
2005\end{array}$ & hatchback & 4,204 & 2,578 \\
\hline W07 & $\begin{array}{c}\text { independent - } \\
\text { MacPherson strut }\end{array}$ & $\begin{array}{l}\text { semi-independent - } \\
\text { with a twist-beam }\end{array}$ & 1,145 & $\begin{array}{c}120,000 / \\
2012\end{array}$ & hatchback & 3,998 & 2,470 \\
\hline W08 & $\begin{array}{l}\text { independent - } \\
\text { MacPherson strut }\end{array}$ & $\begin{array}{l}\text { semi-independent - } \\
\text { with a twist-beam }\end{array}$ & 1,090 & $\begin{array}{c}105,000 / \\
2011\end{array}$ & hatchback & 3,992 & 2,460 \\
\hline
\end{tabular}


for the front axle only, for the rear axle only, and two of them featured no multi-suspension arm systems for the axles. Additionally, the vehicles differed in kerb weights, lengths and wheel bases. They also featured different body types. Four vehicles featured the station wagon bodies, and four others featured the hatchback-type bodies. At the time of the tests, all vehicles were equipped with shock absorbers with a covered mileage of approximately $10,000 \mathrm{~km}$.

For the measurements of the damping coefficient values of shock absorbers, and the measurements of load and mass distribution over the vehicle axles, the Beissbarth STL7000, diagnostics line was used, equipped with a Micro-Swing 6200 module (Fig. 1). The damping coefficient of shock absorbers was characterized with the EUSAMA coefficient.

In the first stage of tests, the influence of the tyre pressure on the changes of the damping coefficient of shock absorbers was identified. The adopted pressure values ranged from 0.13 to $0.29 \mathrm{MPa}$ (Table 3). The grey colour was used for marking normal pressure values for the tested tyres of both vehicles. The following pattern of vehicle loads was employed:

- front axle - for each tyre pressure value, measurements with no load, with a load of $160 \mathrm{~kg}$ distributed evenly in front seats and with a load of $320 \mathrm{~kg}$ distributed evenly in the front seats and rear seats;

- rear axle - for each tyre pressure value, measurements with no load, with a load of $160 \mathrm{~kg}$ distributed evenly in rear seats and with a load of $320 \mathrm{~kg}$ distributed evenly in the front seats and rear seats.

The second stage of the tests was carried out with the same load values and the same distribution of loads in all vehicles. The tests covered eight load variants, according to the pattern presented in Figure 2. The loads were applied with lead weights. They were placed in the front seats, rear seats and in the trunk, with the distribution presented in the pattern (Fig. 2).

The values of the damping coefficient of shock absorbers were defined with the EUSAMA method. The initial frequency of forced input (in this case) was $25 \mathrm{~Hz}$, and the amplitude equalled $6 \mathrm{~mm}$. During the tests, the wheels of one of the vehicle axles were placed on two different plates, and when the forced input system was accelerated by an electric motor to a suitable velocity, the forced input system was switched off, and the measurement and registration of the dynamic pressure of wheels onto plates was effected. When a vehicle was standing on plates, the static pressure of wheels on the plates was registered. The damping coefficient (EUSAMA coefficient) of shock absorbers, calculated during the tests, was the ratio of minimum dynamic pressure $\left(\mathrm{N}_{\mathrm{dmin}}\right)$ to static pressure $\left(\mathrm{N}_{\mathrm{s}}\right)$ of a wheel onto the station plate. It is defined with the following equation:

$$
\mathrm{W}_{\mathrm{ES}}=\frac{\mathrm{N}_{\mathrm{dmin}}}{\mathrm{N}_{\mathrm{S}}} * 100 \%
$$

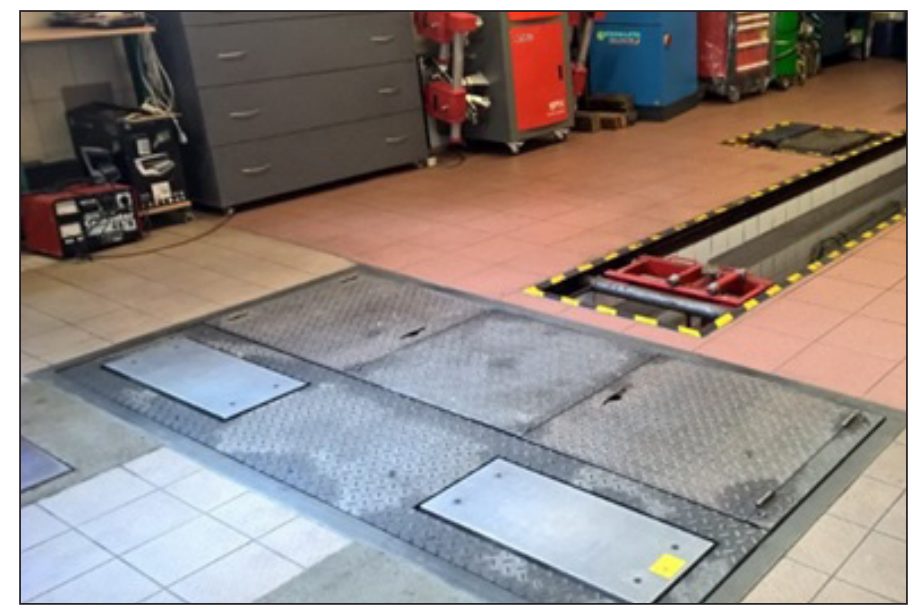

Fig. 1. Beissbarth STL7000 diagnostics line

Table 3. Tyre pressure values adopted for the test

\begin{tabular}{|l|l|l|l|l|l|l|l|l|l|}
\hline & \multicolumn{10}{|c|}{ Tyre pressure values [MPa] } \\
\hline Front axle & 0.29 & 0.27 & 0.25 & 0.23 & 0.21 & 0.19 & 0.17 & 0.15 & 0.13 \\
\hline Rear axle & 0.29 & 0.27 & 0.25 & 0.23 & 0.21 & 0.19 & 0.17 & 0.15 & 0.13 \\
\hline
\end{tabular}




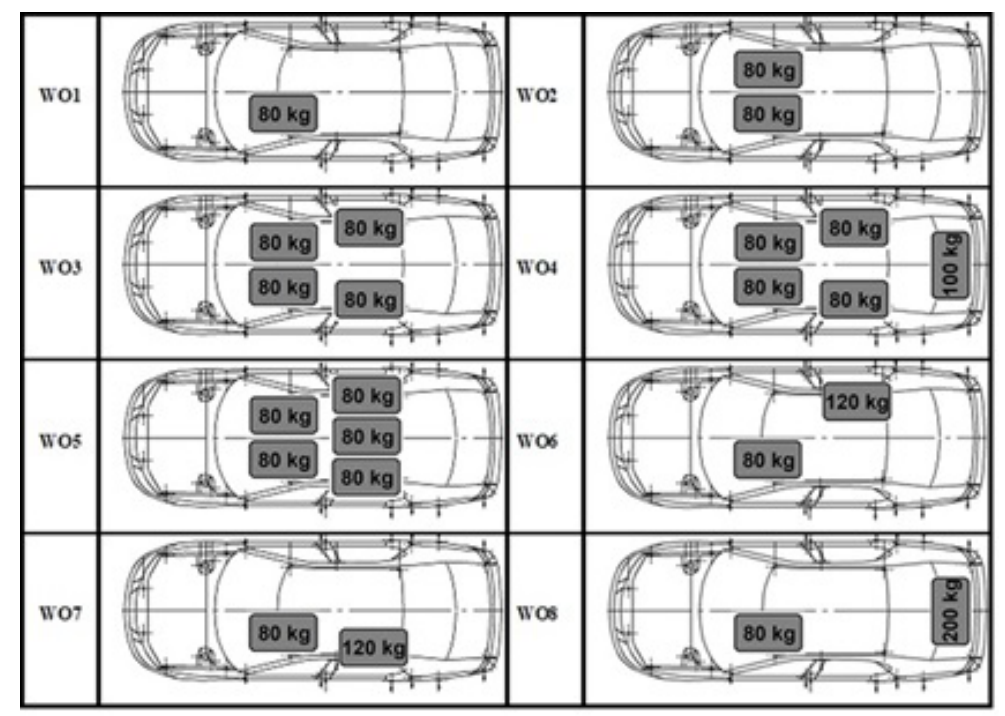

Fig. 2. Mass distribution and load distribution adopted for the tests.

\section{INFLUENCE OF VEHICLE LOADS AND TYRE PRESSURE VALUES ON THE DAMPING COEFFICIENTS OF SHOCK ABSORBERS}

At the stage of using vehicles, the aim was to obtain the highest possible EUSAMA coefficient values. The results of the research on the influence of air pressure in individual tyres and vehicle loads on the EUSAMA coefficient are presented in Figures 3-6. The changes of this coefficient are first provided for the left wheel of the front axle. The results indicate that in an SUV-type vehicle, the EUSAMA coefficient reached much higher values. In this case, the influence of the vehicle load did not cause any significant changes. For a D-segment vehicle, the EUSAMA coefficient was influenced by tyre pressure and loads. Practically over the entire range of changes in tyre pressure values, the lowest EUSAMA coefficients were featured for the unloaded vehicles.

A similar dependence, as in the case of the left wheel of the front axle, was obtained for the right wheel of the rear axle (Fig. 4). However, in this case, there were even greater changes in the EUSAMA coefficients, depending on the tyre pressure in the segment D vehicle. Depending on the tyre pressure, the EUSAMA coefficient changed in the range of $20 \%$ to almost $60 \%$. Especially large changes were found for the no-load cases. In the case of an SUV-type vehicle, depending on the tyre pressure, the EUSAMA coefficient changed far less than in the case of the D-segment vehicle. On the other hand, depending on the load value, the change range was in many cases practically unnoticeable.

For the rear axle, left side (Fig. 5) in the segment $D$ vehicle, smaller changes in the EUSAMA coefficient may be observed than for the front axle. In both categories, a greater influence on the changes of the EUSAMA coefficients was exerted by the tyre pressure than by the vehicle loads. For the SUV-type vehicles, there was no substantial influence of the load changes on the value of the EUSAMA coefficient.

The changes of the EUSAMA coefficient presented in Figure 6, depending on tyre pressure and rear axle load at the right side indicate basically the same interdependencies, as in the case of the second wheel of the same axle.

The obtained difference in the trending changes of the damping coefficient of shock absorbers, depending on the load and tyre pressure in both vehicles stem mainly from the various kerb weights of both vehicles. The larger kerb weight of an SUV-type vehicle is the reason why smaller changes in the EUSAMA coefficient take place depending on the load values. On the other hand, another characteristic of the shock absorber damping in an SUV-type vehicle, which has its centre of gravity located higher, also causes smaller changes in the EUSAMA coefficients than in the D-segment vehicle. 


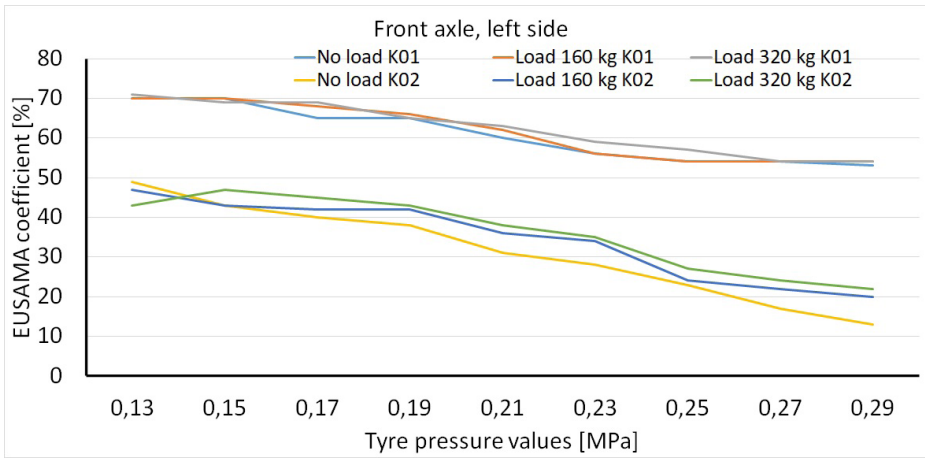

Fig. 3. EUSAMA coefficient trend, depending on the tyre pressure and left side front axle load value in the K01 and K02 vehicles

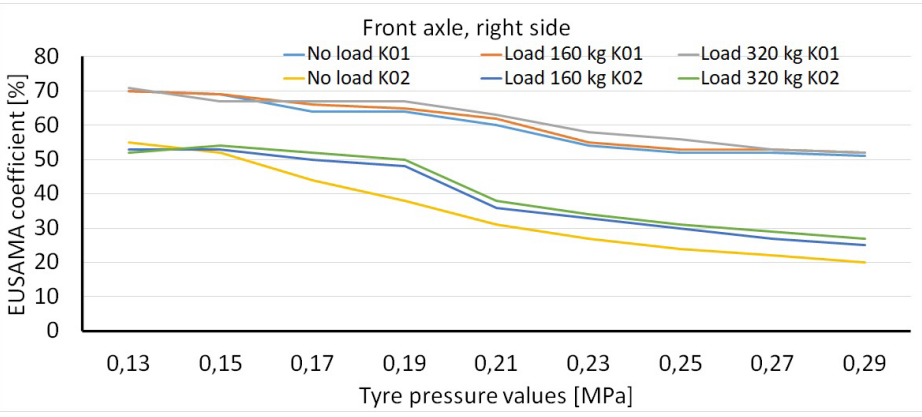

Fig. 4. EUSAMA coefficient trend, depending on the tyre pressure and right side front axle load value in the $\mathrm{K} 01$ and $\mathrm{K} 02$ vehicles

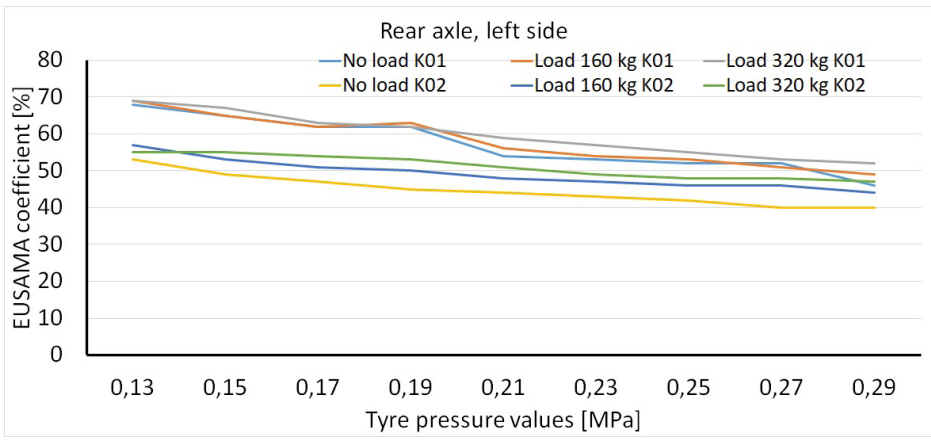

Fig. 5. EUSAMA coefficient trend, depending on the tyre pressure and left side rear axle load value in the $\mathrm{K} 01$ and $\mathrm{K} 02$ vehicles

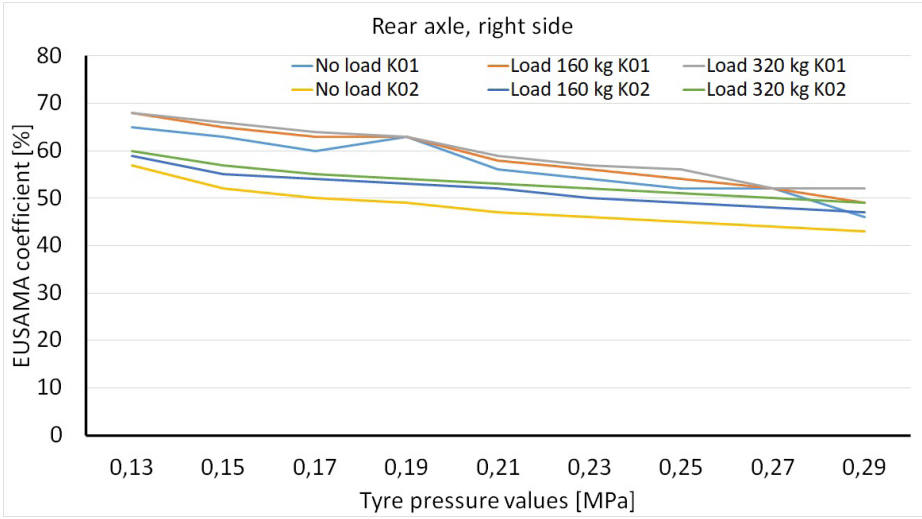

Fig. 6. EUSAMA coefficient trend, depending on the tyre pressure and right side rear axle load value in the $\mathrm{K} 01$ and $\mathrm{K} 02$ vehicles 


\section{INFLUENCE OF THE SIZE AND DISTRIBUTION OF LOAD ON DAMPING COEFFICIENT OF SHOCK ABSORBERS}

The results of the research on the influence of the size and distribution of loads in a vehicle on the value of the damping coefficient of shock absorbers are provided in charts for the vehicles with different suspension systems, kerb weights, lengths and wheel bases. Figures 7 and 8 present the results for the vehicles (P01 and P02, respectively) with multi-suspension arms for the front and rear axles (the longest ones) with the largest wheelbases and kerb weights. It may be stated that especially large changes in the damping coefficient of shock absorbers (EUSAMA coefficient), depending on the size and distribution of loads were found for the rear axle. The range of the changes varied from approximately $50 \%$ to close to $75 \%$ and the higher values of the EUSAMA coefficient were for vehicle loads of $80 \mathrm{~kg}$ in the driver's seat and $200 \mathrm{~kg}$ in the trunk (variant No. 8). High values of the coefficient were also noted for the variant No. 4, in which the load of $100 \mathrm{~kg}$

a)

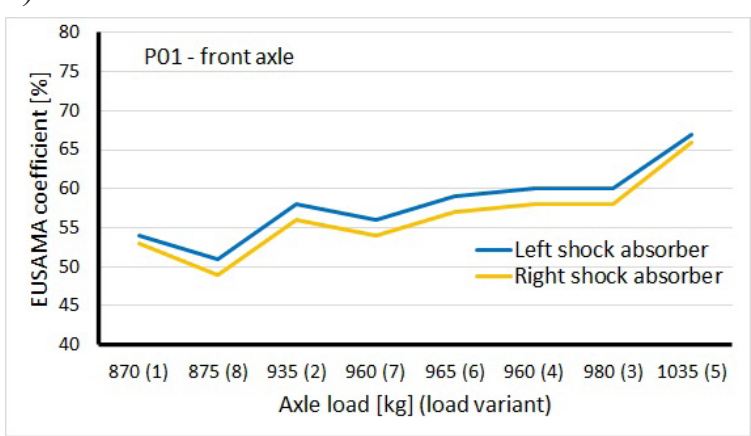

was located in the trunk and $320 \mathrm{~kg}$ in the passenger space, as well as in the variant No. 5, with a load of $400 \mathrm{~kg}$ located in the passenger space. On the other hand, the smallest value of the damping coefficient of shock absorbers was defined for the loads distributed in the driver's seat only (variant No. 1) and in the front seats of the driver and the passenger (variant No. 2). In the case of the front axle, the change of the EUSAMA coefficient, depending on the load values, was smaller, as the difference reached $15 \%$ at maximum. For this axle, the smallest values were determined for the variant No. 8, with a load of $200 \mathrm{~kg}$ located in the trunk and a load of $80 \mathrm{~kg}$ located in the driver's seat. The values were smaller than with the load of $80 \mathrm{~kg}$ located in the driver's seat only. By far, the largest values of the EUSAMA coefficient were noted for the vehicle load of $400 \mathrm{~kg}$ distributed in the passenger space.

Very similar dependencies, both for the front and the rear axle, were determined for the $\mathrm{R} 03$ (Fig. 9) and R04 vehicles (Fig. 10), which featured varied rear axle suspension systems with a twist-beam. The kerb weights as well their lengths

Fig. 7. EUSAMA coefficient trend, depending on the load in the P01 vehicles:

a) front axle; b) rear axle

a)

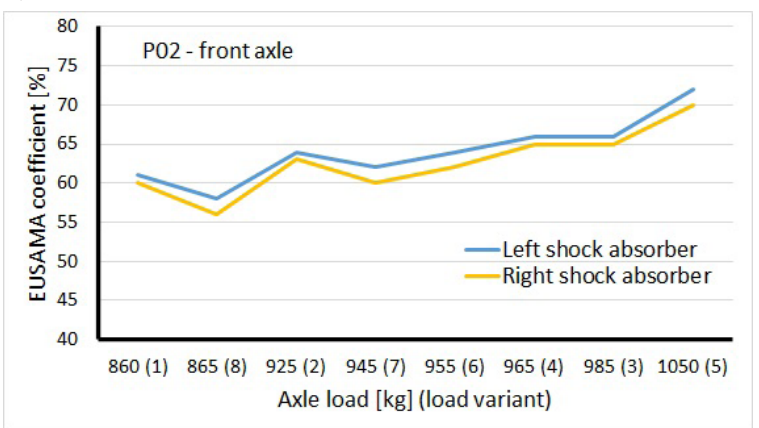

b)

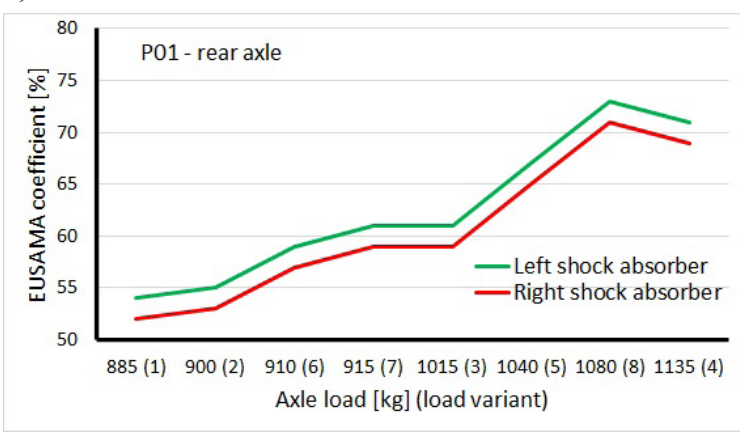

Fig. 8. EUSAMA coefficient trend, depending on the load in the P02 vehicles:

a) front axle; b) rear axle 
and wheelbases of these vehicles were similar. The difference between the smallest and the largest values of the damping coefficient of shock absorbers for the front axle also reached approximately $15 \%$ and $25 \%$ for the rear axle. Moreover, the EUSAMA coefficient with the largest and the smallest values was reported for the same load variants, as in the case of previous vehicles. Taking the above into the account, it may be stated that the suspension system type does not play a considerable role with respect to the changes in the EUSAMA coefficient values, depending on the loads in passenger vehicles.

For the T05 and T06 vehicles, for which the test results of the changes in the EUSAMA coefficient, depending on the size and distribution of load, are provided in Figures 11 and 12, respectively, different trend curves than in the case of previous vehicles were obtained. The vehicles had multi-suspension arms for the rear axles only. The rear axles were reported with a considerably smaller range of changes in the damping coefficient of shock absorbers, depending on the tested load variant, than in the case of the first four vehicles. In this case, the EUSAMA coefficient reached the value from approximately $55 \%$ to approximately $65 \%$. For these vehicles, the highest values were also determined for the load variant No. 8, with the load in the driver's seat accompanied by a load of $200 \mathrm{~kg}$ in the trunk. Slightly smaller values of the coefficient were determined for the load variants No. 5 and No. 4. These involved the total load of $400 \mathrm{~kg}$ distributed over the entire passenger space (variant No. 5) and the load of $320 \mathrm{~kg}$ located in the passenger space and $100 \mathrm{~kg}$ in the trunk (variant No. 4), respectively. The smallest values for the damping coefficient of shock absorbers were registered for the load of $80 \mathrm{~kg}$ in the driver's seat. On the other hand, for the front axles of the described vehicles, it was determined that the range of changes of the EUSAMA coefficient, depending on the load variant, was much larger than for the first four of the described vehicles. The range of changes was approximately $25 \%$. The smallest values were reported for the load variant No. 8 , with $80 \mathrm{~kg}$ located in the driver's seat and $200 \mathrm{~kg}$ in the trunk. Additionally, relatively small values of the a)

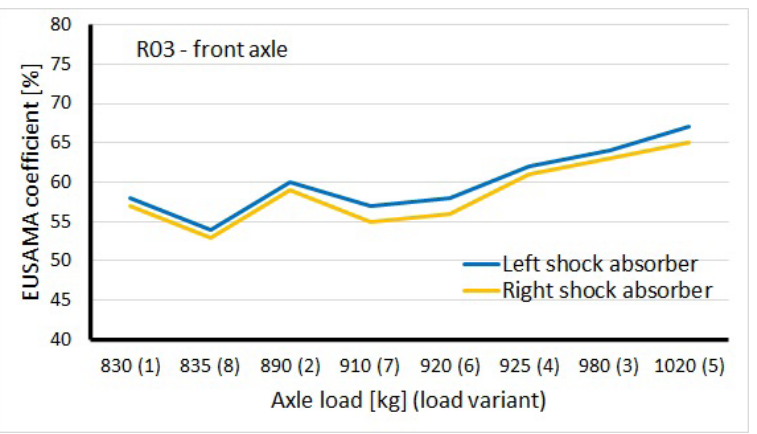

b)

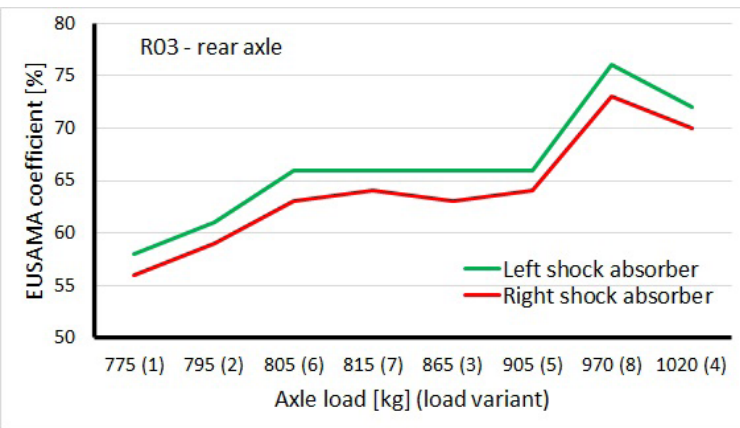

Fig. 9. EUSAMA coefficient trend, depending on the load in the R03 vehicles: a) front axle; b) rear axle

a)

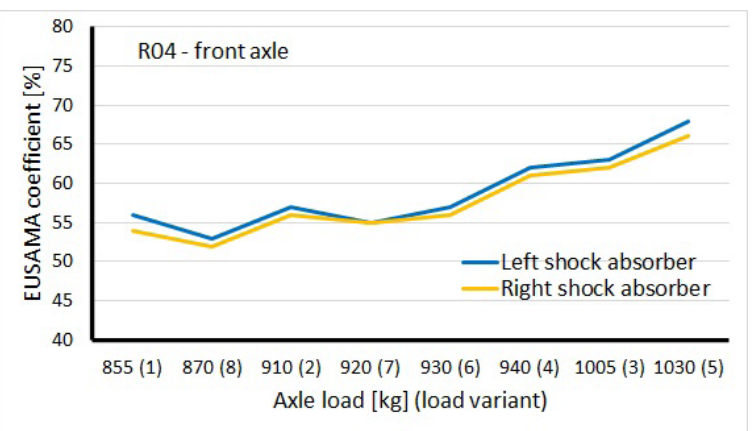

b)

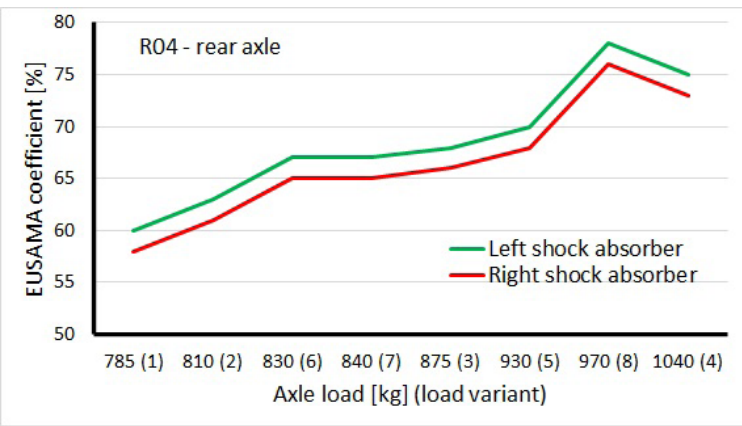

Fig. 10. EUSAMA coefficient trend, depending on the load in the R04 vehicles:

a) front axle; b) rear axle 
a)

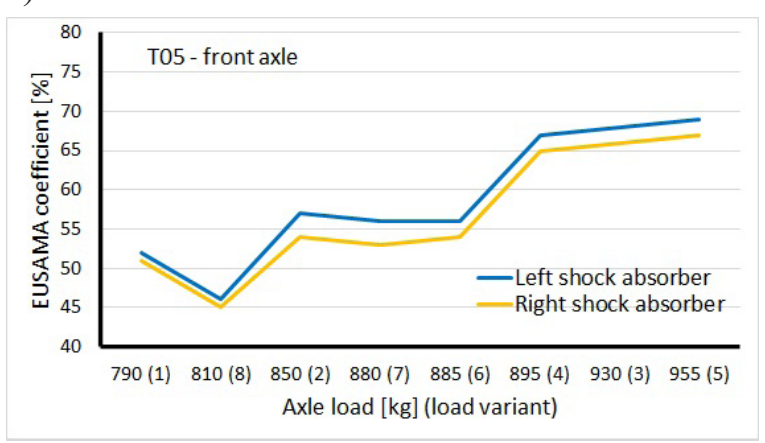

b)

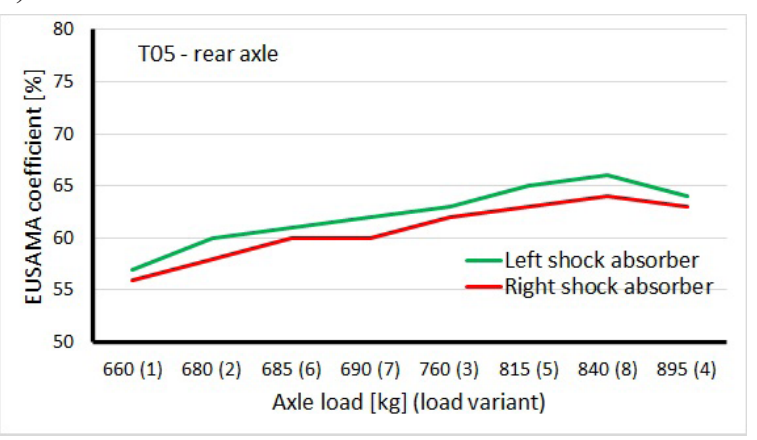

Fig. 11. EUSAMA coefficient trend, depending on the load in the T05 vehicles: a) front axle; b) rear axle

a)

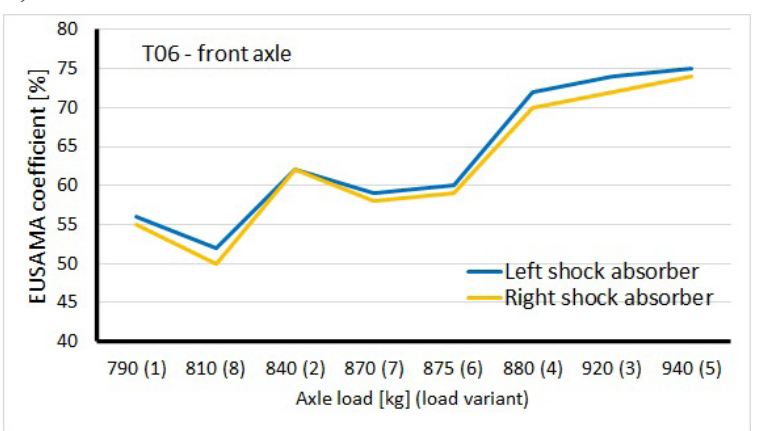

b)

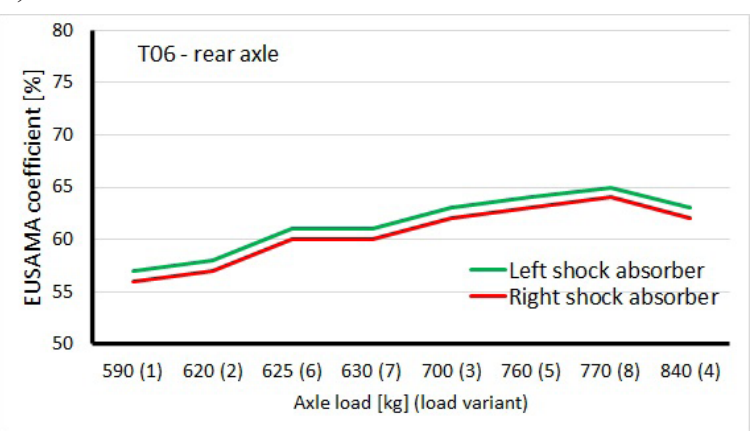

Fig. 12. EUSAMA coefficient trend, depending on the load in the T06 vehicles: a) front axle; b) rear axle

EUSAMA coefficient were noted for the variant No. 1, with a load of $80 \mathrm{~kg}$ in the driver's seat only and for the variants No. 7 and 6, in which the load of $120 \mathrm{~kg}$ was located, either on the left or right rear seat, respectively.

In the last two vehicles, practically the same trend curves were obtained, picturing the changes of the EUSAMA coefficient, depending on the size and distribution of the load, as in the previous vehicles (T05 and T06). The results were compiled for the vehicles W07 and W08, respectively, and presented in Figures 13 and 14. These were the vehicles with the simplest suspension systems, as the MacPherson struts were used for front axles and twist beams for rear axles. The range of changes of the damping coefficient of shock absorbers, depending on the used variant, was approximately $25 \%$ for the front axle and approximately $10 \%$ for the rear axle.

The presented changes provide for the possibility of defining a series of interdependencies. Reporting similar results for the front and rear axles in the first four vehicles and then for the last four vehicles shows the lack of influence of the suspension system on the EUSAMA coefficient, depending on the size and distribution of the load. The changes are closely connected with the vehicle lengths, wheelbases and kerb weights. For example, in the case of the vehicles No. 1-4, which were longer, with larger wheelbases and kerb weights, the change of loads spurred a large rage of the EUSAMA coefficient changes for the rear axles and relatively small for the front axles. In the vehicles No. 5-6, relatively small changes were also featured for the rear axles and large ones for the front axles.

In each of the tested vehicles, both for the front axles and rear axles, practically in all load variants, slightly smaller values of the damping coefficient of shock absorbers on the right side were found.

\section{CONCLUSION}

The test results indicate that when using a vehicle under varied load conditions, there are changes in the damping coefficient of shock 
a)

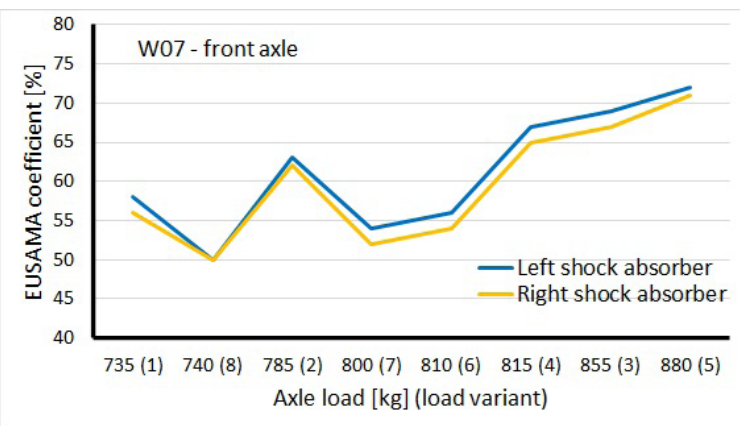

b)

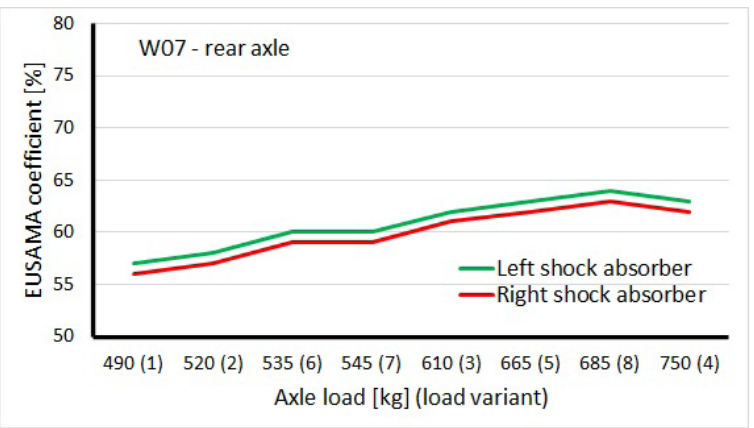

Fig. 13. EUSAMA coefficient trend, depending on the load in the W07 vehicles: a) front axle; b) rear axle.

a)

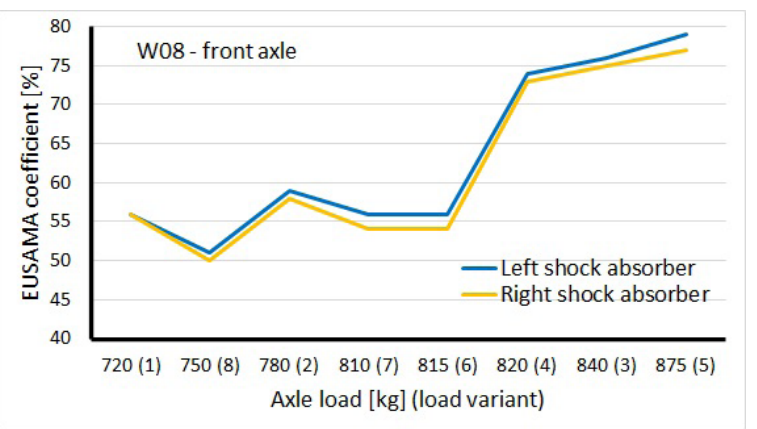

b)

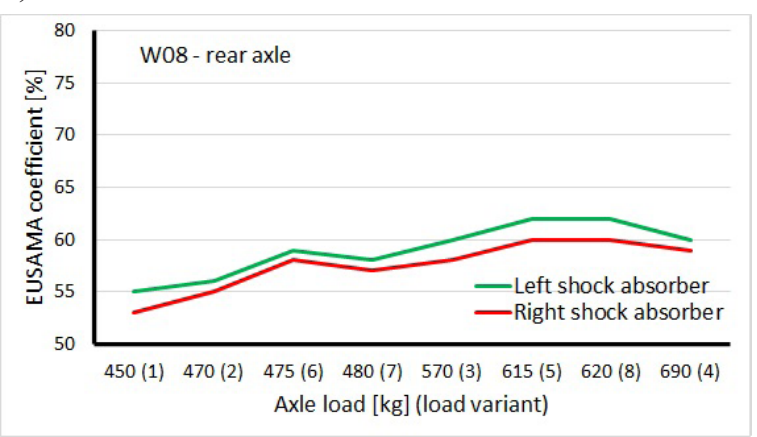

Fig. 14. EUSAMA coefficient trend, depending on the load in the W08 vehicles:

a) front axle; b) rear axle

absorbers. This may translate directly into the traction characteristics and stability of a vehicle while travelling, and this, in turn, is connected with the vehicle's safety.

This paper shows the considerable influence of the tyre pressure on the EUSAMA coefficient. This was particularly visible for the front axle of the D-segment vehicle (according to the European classification) where, together with the tyre pressure change, the changes in the damping coefficient of shock absorbers reached over $30 \%$. In an SUV-type vehicle, the changes were smaller and reached approximately $15 \%$. For the rear axle, smaller values were noted between both vehicles. The changes in the vehicle loads also influenced the values of the damping coefficient of shock absorbers.

The changes in the damping coefficient of shock absorbers were also influenced by the size and distribution of loads in vehicles. It was determined that the largest values of the EUSAMA coefficient are reached with the loads located in the driver's seats and in trunks and the smallest values were reported for loads located in the driver's seats only. For the front axles, the smallest values of the EUSAMA coefficient were featured with loads located in the driver's seats and in the trunk and the largest values were determined for vehicle loads of $400 \mathrm{~kg}$, distributed evenly in the passenger space.

Although no dependencies were determined between the vehicle suspension system types and the EUSAMA coefficient, depending on the size and distribution of loads, the crucial influence on the value of this coefficient was exerted by the vehicle kerb weights, their lengths and wheelbases. In the vehicles with larger kerb weights and wheelbases, longer and larger changes in the EUSAMA coefficients were observed for rear shock absorbers with individual load variants. The changes amounted to approximately $25 \%$. On the other hand, in smaller vehicles, the changes reached approximately $10 \%$. A reverse dependency was observed for the front axles. In smaller vehicles, the range of changes of the EUSAMA coefficients reached approximately $25 \%$ and for larger vehicles, the changes reached approximately $15 \%$. 


\section{REFERENCES}

1. Aguilar J.J., Sanz M., Guillomía D., Lope M. and Bueno I. Analysis, characterization and accuracy improvement of optical coordinate measurement systems for car body assembly quality control. International Journal Advanced Manufacturing Technology, 30, 2006, 1174-1190.

2. Ahrens G., Dellmann T., Gies S., Hecht M., Hefazi H., Henke R., Pischinger S., Schaufele R. and Tegel O. Applications in Mechanical Engineering. Transport Systems Würzburg: Springer Science+Business Media, 2009.

3. Al-Zughaibi A., Xue Y. and Grosvenor R. A new insight into modelling passive suspension real test rig system with consideration of nonlinear friction forces. Proceedings of the Institution of Mechanical Engineers Part D Journal of Automobile Engineering, 2018, 1-26.

4. Bae S., Lee J.M., Choi W.J., Yun J..R., Tak TO. Axiomatic approach to the kinematic design of an automotive suspension system with the McPherson strut type. International Journal of Vehicle Design, 31, 2003, 58-71.

5. Chen B., Liu Y. and Shi W. Suspension Optimization Design and Virtual Prototype Simulation Analysis of FSAE Racing Car. Journal of Physics Conference Series, 2019, 1176.

6. Dukkipati R.V. and Vallurupalli S.S. Smart active suspension to counteract dynamic load changes during critical maneuvers. JSME International Journal Series C, 43, 2000, 259-272.

7. Durmaz B.E., Kacmaz B., Mutlu I. and Turan Söylemez M. Implementation and Comparison of LQR-MPC on Active Suspension System. Proc. of 10th International Conference on Electrical and Electronics Engineering (ELECO), Bursa 2019.

8. Gonera J. and Napiórkowski J. Model for forecasting the geometry of the floor panel of a passenger car during its operation. Eksploatacja i Niezawodność - Maintenance and Reliability, 20(4), 2018, 689-695.

9. Hyniova K. One-Quarter-Car Active Suspension Model Verification. Proc of The 2016 International Conference Applied Mathematics, Computational
Science and Systems Engineering ITM Web of Conferences 2017.

10. Livesey W.A., Robinson A. The repair of vehicle bodies. Oxford: Butterworth-Heinemann, 2006.

11. Omar M., El-Kassaby M.M. and Abdelghaffar W.A. Parametric numerical study of electrohydraulic active suspension performance against passive suspension. AEJ - Alexandria Engineering Journal, 57, 2018, 3609-3614.

12. Ramalingam M. and Jebaseelan D. The effect of vibration characteristics of an automotive seating system on ride comfort - A finite element study. ARCHIVE Proceedings of the Institution of Mechanical Engineers Part C Journal of Mechanical Engineering Science, 223, 2019, 6588-6601.

13. Rychlik A., Vrublevskyi O. and Prokhorenko A. Modelling of the diagnostic station operation process to identify damage to the wheel rim structure. Journal of Mechanical Science and Technology, 33 (9), 2019, 4129-4138.

14. Shao X., Naghdy F., Du H. and Qin Y. Coupling effect between road excitation and an in-wheel switched reluctance motor on vehicle ride comfort and active suspension control. Journal of Sound and Vibration, 443, 2018, 683-702.

15. Shi Q., Peng C., Chen Y. and He J. Robust kinematics design of MacPherson suspension based on a double-loop multi-objective particle swarm optimization algorithm. Proceedings of the Institution of Mechanical Engineers Part D Journal of Automobile Engineering, 223, 2019, 3263-3278.

16. Shim T. and Velusamy PC. Suspension design and dynamic analysis of a lightweight vehicle. International Journal of Vehicle Design, 43, 2007, 258-280.

17. Vidya V. and Dharmana MM. Model Reference Based Intelligent Control of an Active Suspension System for Vehicles. Proc. of International Conference on Circuit, Power and Computing Technologies (ICCPCT) 2017.

18. Wallentowitz H. Virtuelle FahrzeugentwicklungNetzwerkeals Voraussetzungenzur Problemlosung. Erfolg in Netzwerken. Berlin: Springer - Verlag Berlin Heidelberg, 2002. 